\title{
The difference of use of CT in the general versus pediatric emergency departments for adolescent patients in the same tertiary hospital
}

\author{
Seul Ki Kim', Jin Hee Jung ${ }^{2,3}$, Jin Hee Lee ${ }^{4}$, Jae Yun Jung', \\ Hyuksool Kwon², So Hyun Paek', Young Ho Kwak', Do Kyun Kim \\ 'Department of Emergency Medicine, Seoul National University Hospital, Seoul, Korea \\ ${ }^{2}$ Department of Emergency Medicine, Seoul Metropolitan Government Seoul National University Boramae \\ Medical Center, Seoul, Korea \\ ${ }^{3}$ Department of Preventive Medicine, Kangwon National University School of Medicine, Chuncheon, Korea \\ ${ }^{4}$ Department of Emergency Medicine, Seoul National University Bundang Hospital, Seongnam, Korea
}

Objective The use of computed tomography (CT) in pediatric patients has decreased since the association between radiation and cancer risk has been reported. However, in adolescent patients being treated as adult patients, there has been a high incidence of CT use in emergency departments (EDs). Thus, this study aimed to evaluate the CT use in adolescent patients with complaints of headache or abdominal pain in the general and pediatric EDs of the same hospital.

Methods A retrospective chart review of patients aged 15 to 18 years, who presented with headache or abdominal pain at the general and pediatric EDs of Seoul National University Hospital from January 2010 to December 2014, was conducted.

Results A total of 407 adolescent patients with complaints of headache and 980 with abdominal pain were included in this study. The adolescent patients in the general ED were more likely to undergo $\mathrm{CT}$ scans than those in the pediatric ED, with both patients having headache (42.4\% vs. $20.5 \%$, respectively, $\mathrm{P}<0.001)$ and abdominal pain $(29.0 \%$ vs. $18.4 \%$, respectively, $\mathrm{P}<0.001)$. There was no statistical difference in the rates of positive $\mathrm{CT}$ findings between the general and pediatric EDs. The frequency of visits to the general ED was associated with high rates of CT use in adolescent patients with complaints of headache (odds ratio, 3.95; 95\% confidence interval, 2.01 to 7.77 ) and those with abdominal pain (odds ratio, 1.76; 95\% confidence interval, 1.18 to 2.64).

Conclusion The ED setting influences the use of CT on adolescent patients, and a child-friendly environment could reduce the radiation risks.

Keywords Adolescent; Computed tomography; Emergency service, hospital; Radiation exposure
elSSN: 2383-4625

Received: 12 September 2017

Revised: 2 November 2017

Accepted: 2 November 2017

Correspondence to: Do Kyun Kim Department of Emergency Medicine, Seoul National University Hospital, 101 Daehak-ro, Jongno-gu, Seoul 03080, Korea

E-mail:birdbeak@snuh.org ORCID

http://orcid.org/0000-0002-6144-302X

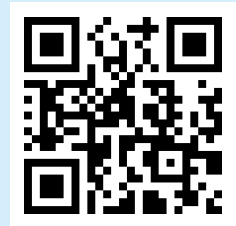

How to cite this article:

Kim SK, Jung JH, Lee JH, Jung JY, Kwon $H$, Paek SH, Kwak YH, Kim DK. The difference of use of $\mathrm{CT}$ in the general versus pediatric emergency departments for adolescent patients in the same tertiary hospital. Clin Exp Emerg Med 2019;6(1):19-24.

This is an Open Access article distributed under the terms of the Creative Commons Attribution Non-Commercial License (http:// creativecommons.org/licenses/by-nc/4.0/). 


Wapsule $\begin{aligned} & \text { What is already known } \\ & \text { Despite the decreasing use of computed tomography (CT) in pediatric patients, the frequency of CT use in adolescent } \\ & \text { patients, treated as adult patients, who visit the emergency departments (EDs) remains high. }\end{aligned}$
$\begin{aligned} & \text { What is new in the current study } \\ & \text { We demonstrated that the decision to use CT in adolescent patients may differ even within the same hospital, depend- } \\ & \text { ing on the ED environment. The ED setting can influence the use of CT in adolescents, and a child-friendly environment } \\ & \text { could reduce the radiation risks. }\end{aligned}$

\section{INTRODUCTION}

The use of computed tomography (CT) in pediatric patients who visit the emergency department (ED) has increased as the number of patients increases every year. ${ }^{1,2}$ Many studies have reported that pediatric patients are at greater risk of developing cancer due to radiation exposure than adult patients. ${ }^{3-5}$ As concerns about cancer risks have increased, CT use in pediatric patients has started to decrease in the last decade. ${ }^{4,6-8}$

Several well-known risk factors are associated with the use of $\mathrm{CT}$ in pediatric patients who visit the ED. Several studies have reported that the use of $\mathrm{CT}$ was more frequent among children who are seen in adult-focused EDs or facilities. ${ }^{9,10}$ Moreover, the radiation risks associated with $\mathrm{CT}$ use in adolescent patients are lower than those in young children, but previous studies have demonstrated a more pronounced increase of CT utilization in adolescent patients. ${ }^{2,8,10,11}$

Seoul National University Hospital operates separate pediatric and general EDs; thus, the emergency medicine (EM) residents rotate between both EDs, and when visiting an ED, adolescent patients can choose one of the two EDs without restriction. Hence, we hypothesized that adolescent patients in the pediatric ED might undergo fewer CT scans than those who attend the general ED because of their increased awareness on the risks of radiation in the pediatric ED. We reviewed the data from adolescent patients who presented with headache or abdominal pain, which are among the most common complaints in the ED. This study aimed to assess the difference in the CT utilization between both groups and identify the modifying factors that can reduce the radiation risk in adolescent patients.

\section{METHODS}

\section{Study design and population}

A retrospective chart review was conducted on adolescent pa- tients aged 15 to 18 years old who presented with complaints of headache or abdominal pain to the general or pediatric ED of Seoul National University Hospital over a 5-year period (January 2010 to December 2014). Seoul National University Hospital is an urban, academic tertiary hospital and has both general and pediatric EDs.

The collected data included the numbers of CT scans performed in the two EDs, medical histories, analgesic use, histories of trauma, histories of brain or abdominal surgery, any imaging in the 6 months prior to the ED visit, Emergency Severity Index triage lev$\mathrm{el}$, and disposition. Patients who visited the ED with trauma were excluded from the study.

The primary outcome of this study was the comparison of the rates of CT scans in adolescent patients with headache or abdominal pain between the two EDs. The secondary objective was to identify the risk factors associated with CT use utilizing both univariate and multivariate analyses.

The brain CT scans were considered positive if they revealed the presence of an intracranial lesion (intracranial hemorrhage, brain mass, or hydrocephalus), and the abdominal/pelvic CT scans were considered positive if they revealed an intraabdominal lesion (bowel obstruction, ileus, urolithiasis, appendicitis, diverticulitis, inflammatory bowel disease, intraabdominal abscess, abdominal aortic aneurysm, hepatobiliary disease, ischemic bowel, pyelonephritis, or gynecologic disease) that required surgical intervention, admission, or outpatient follow-up. This study was approved by the institutional review board (1511-052-718). Informed consent was waived due to the retrospective design.

\section{Data analysis}

Normally distributed data were compared using t-tests. For unadjusted comparisons, categorical data were compared using chisquare tests. $P=0.05$ was set as the threshold for statistical significance. A multivariable logistic regression model was then used to estimate the odds ratios (ORs) of the factors associated with 
CT use. We used CT scan as the dependent variable and other characteristics including ED setting (general vs. pediatric) as the independent variables of interests. The covariates of the model associated with CT use were selected using a hierarchical stepwise regression (adjusted Wald test) with $\mathrm{P}<0.20$ as cutoff for inclusion. The data were analyzed using the IBM SPSS Statistics ver. 22.0 (IBM Corp., Armonk, NY, USA).

\section{RESULTS}

During the 5-year study period, a total of 407 patients with headache were found eligible for inclusion; 158 (38.8\%) of these patients visited the general ED, and 249 (61.2\%) visited the pediatric ED. A total of 980 eligible patients with abdominal pain visited the EDs in the same period, including 458 (46.3\%) patients who visited the general ED and 522 (53.3\%) who visited the pediatric ED.

The mean age of patients who visited the general ED was older than those who visited the pediatric ED in both the headache and abdominal pain groups (headache: 17.2 vs. $15.8, \mathrm{P}<0.001$; abdominal pain: 17.3 vs. $15.8, \mathrm{P}<0.001)$. Sex, past surgical history, and triage acuity level were similar between the two groups. The patients with headache or abdominal pain who visited the pediatric ED were found to have a higher percentage of an underlying disease. In the headache group, the overall admission rates were similar between the two EDs; however, in the abdominal pain group, the rate of admission to the pediatric ED was higher than that in the general ED (Table 1).

Table 1. Patient characteristics

\begin{tabular}{|c|c|c|c|c|c|c|c|c|}
\hline \multirow[b]{2}{*}{ Presenting complaint } & \multicolumn{4}{|c|}{ Headache } & \multicolumn{4}{|c|}{ Abdominal pain } \\
\hline & $\begin{array}{c}\text { General ED } \\
(n=158)\end{array}$ & $\begin{array}{l}\text { Pediatric ED } \\
(n=249)\end{array}$ & $\begin{array}{l}\text { All patients } \\
(\mathrm{n}=407)\end{array}$ & P-value & $\begin{array}{c}\text { General ED } \\
(n=458)\end{array}$ & $\begin{array}{l}\text { Pediatric ED } \\
(n=522)\end{array}$ & $\begin{array}{l}\text { All patients } \\
(n=980)\end{array}$ & P-value \\
\hline Age (yr) & & & & $<0.001$ & & & & $<0.001$ \\
\hline Mean, \pm SD & $17.2 \pm 0.1$ & $15.8 \pm 0.1$ & $16.3 \pm 0.1$ & $<0.001$ & $17.3 \pm 0.1$ & $15.8 \pm 0.1$ & $16.5 \pm 0.1$ & $<0.001$ \\
\hline 15 & $4(2.5)$ & $125(50.2)$ & $129(31.7)$ & & $11(2.4)$ & $245(46.9)$ & $256(26.1)$ & \\
\hline 16 & $31(19.6)$ & $68(27.3)$ & $99(24.3)$ & & $69(15.1)$ & $160(30.7)$ & $229(23.4)$ & \\
\hline 17 & 59 (37.3) & $39(15.7)$ & $98(24.1)$ & & $143(31.2)$ & $85(16.3)$ & $228(23.3)$ & \\
\hline 18 & $64(40.5)$ & $17(6.8)$ & 81 (19.9) & & $235(51.3)$ & $32(6.1)$ & $267(27.2)$ & \\
\hline Sex, male & $86(54.4)$ & $126(50.6)$ & $212(52.1)$ & 0.477 & $189(41.3)$ & $232(44.4)$ & $421(43.0)$ & 0.332 \\
\hline Any underlying disease & $49(31.0)$ & $123(49.4)$ & $172(42.3)$ & $<0.001$ & $125(27.3)$ & $230(44.1)$ & $355(36.2)$ & $<0.001$ \\
\hline Operation history & $13(8.2)$ & $39(15.7)$ & $52(12.8)$ & 0.033 & $62(13.5)$ & 66 (12.6) & $128(13.1)$ & 0.705 \\
\hline Any imaging within 6 months & $6(3.8)$ & $18(7.2)$ & $24(5.9)$ & 0.196 & $20(4.4)$ & $61(11.7)$ & $81(8.3)$ & $<0.001$ \\
\hline Analgesic use & $117(74.1)$ & 135 (54.2) & 252 (61.9) & $<0.001$ & 153 (33.4) & $149(28.5)$ & $302(30.8)$ & 0.111 \\
\hline High triage acuity & 154 (97.5) & $236(94.8)$ & $390(95.8)$ & 0.214 & 452 (98.7) & $501(96.0)$ & 953 (97.2) & 0.010 \\
\hline Disposition & & & & 0.874 & & & & $<0.001$ \\
\hline Discharge & $133(84.2)$ & $211(84.7)$ & $344(84.5)$ & & 377 (82.3) & $368(70.5)$ & 745 (76.0) & \\
\hline Ward & $23(14.6)$ & 34 (13.7) & $57(14.0)$ & & $46(10.0)$ & $148(28.4)$ & 194 (19.8) & \\
\hline ICU & $2(1.3)$ & $3(1.2)$ & $5(1.2)$ & & $4(0.9)$ & $2(0.4)$ & $6(0.6)$ & \\
\hline Transfer & $0(0.0)$ & $1(0.4)$ & $1(0.2)$ & & $31(6.8)$ & $2(0.4)$ & $33(3.4)$ & \\
\hline Death & $0(0.0)$ & $0(0.0)$ & $0(0.0)$ & & $0(0.0)$ & $2(0.4)$ & $2(0.2)$ & \\
\hline Admitted & 25 (15.8) & 38 (15.3) & 63 (15.5) & 0.878 & $81(17.7)$ & $154(29.5)$ & $235(24.0)$ & $<0.001$ \\
\hline
\end{tabular}

Values are presented as number (\%) unless otherwise indicated. Imaging indicates abdominal sonography, abdominal or brain computed tomography, brain magnetic resonance imaging; simple X-ray was excluded. High triage was defined as Emergency Severity Index level 1, 2, and 3.

$E D$, emergency department; ICU, intensive care unit.

Table 2. Comparison of CT scans of general and pediatric ED

\begin{tabular}{|c|c|c|c|c|c|c|c|c|}
\hline \multirow[b]{2}{*}{ Presenting complaint } & \multicolumn{4}{|c|}{ Headache } & \multicolumn{4}{|c|}{ Abdominal pain } \\
\hline & $\begin{array}{c}\text { General ED } \\
(n=158)\end{array}$ & $\begin{array}{l}\text { Pediatric ED } \\
(n=249)\end{array}$ & $\begin{array}{l}\text { All patients } \\
(n=407)\end{array}$ & P-value & $\begin{array}{c}\text { General ED } \\
(n=458)\end{array}$ & $\begin{array}{l}\text { Pediatric ED } \\
(n=522)\end{array}$ & $\begin{array}{l}\text { All patients } \\
(n=980)\end{array}$ & P-value \\
\hline CT & $67(42.4 \%)$ & $51(20.5 \%)$ & $118(29.0 \%)$ & $<0.001$ & $133(29.0 \%)$ & $96(18.4 \%)$ & $229(23.4 \%)$ & $<0.001$ \\
\hline Positive CT scan & $4 / 67(6.0 \%)$ & $4 / 51(7.8 \%)$ & $8 / 118(6.8 \%)$ & 0.708 & $81 / 133(60.9 \%)$ & $54 / 96(56.3 \%)$ & $135 / 225(60.0 \%)$ & 0.480 \\
\hline CT scans within 6 months & $5 / 158(3.2 \%)$ & $12 / 249(4.8 \%)$ & $17 / 407(4.2 \%)$ & 0.416 & $19 / 458(4.1 \%)$ & $41 / 522(7.9 \%)$ & $60 / 980(6.1 \%)$ & $<0.001$ \\
\hline
\end{tabular}

$\mathrm{CT}$, computed tomography; ED, emergency department. 
Table 3. Multivariable analysis for risk factors related to computed tomography scan in headache patients

\begin{tabular}{lcc}
\hline & Odds ratio & 95\% confidence interval \\
\hline ED & & \\
General ED & 3.95 & $2.01-7.77$ \\
Pediatric ED & 1.00 & \\
Age (yr) & & \\
15 & 1.00 & $0.26-1.33$ \\
16 & 0.59 & $0.44-2.25$ \\
17 & 0.99 & $0.33-2.01$ \\
18 & 0.82 & $0.72-1.95$ \\
Sex & & \\
Male & 1.18 & \\
Female & 1.00 & $0.91-2.74$ \\
Analgesic use & & \\
Yes & 1.58 & $0.68-2.23$ \\
No & 1.00 & \\
Underlying disease & & $0.77-4.63$ \\
Any & 1.23 & \\
None & 1.00 & \\
History of brain operation & 1.89 & \\
Yes & 1.00 & \\
No & & \\
\hline
\end{tabular}

ED, emergency department.

CT use was more frequent in the general ED than in the pediatric ED in both the headache $(42.4 \%$ vs. $20.5 \%, P<0.001)$ and abdominal pain ( $29.0 \%$ vs. $18.4 \%, \mathrm{P}<0.001)$ groups (Table 2$)$. No significant difference was noted in the rates of positive CT findings between the two EDs in either the headache (6.0\% vs. 7.8\%, $\mathrm{P}=0.71)$ or abdominal pain group $(60.9 \%$ vs. $56.3 \%, \mathrm{P}=0.48)$. However, when the whole abdominal pain group was analyzed, irrespective of whether CT was performed or not, a significant difference in the rates of positive $\mathrm{CT}$ findings was found between both EDs (17.7\% vs. $10.3 \%, P<0.001)$, whereas those in the headache group showed no significant difference (2.5\% vs. $1.6 \%, \mathrm{P}=0.51)$.

In a multivariate logistic regression analysis model, the frequency of CT use in adolescent patients was significantly different between the EDs in both patient groups. In the headache group, visits to the general ED were a significant risk factor for obtaining CT scans, with an OR of 3.95 (95\% confidence interval [Cl], 2.01 to 7.77) (Table 3). In the abdominal pain group, visits to the general ED were also a significant risk factor for $\mathrm{CT}$ scans but with an OR only of 1.76 ( $95 \% \mathrm{Cl}, 1.18$ to 2.64$)$ (Table 4).

The presence of an underlying disease is a very important determinant when deciding to use $\mathrm{CT}$ in the ED. Due to the increased prevalence of an underlying disease in patients admitted to the pediatric ED, additional comparisons were made after excluding these patients. The rate of CT utilization was significantly lower in the pediatric ED among the headache group (43.1\% vs. 13.5\%,
Table 4. Multivariable analysis for risk factors related to CT scan in patients with abdominal pain

\begin{tabular}{lcc}
\hline & Odds ratio & $\begin{array}{c}95 \% \text { confidence } \\
\text { interval }\end{array}$ \\
\hline ED & & \\
$\quad$ General ED & 1.76 & $1.18-2.64$ \\
$\quad$ Pediatric ED & 1.00 & \\
Age (yr) & & \\
15 & 1.00 & \\
16 & 1.28 & $0.76-1.91$ \\
17 & 1.00 & $0.60-1.67$ \\
18 & 1.02 & $0.60-1.76$ \\
Sex & & \\
Male & 1.01 & $0.75-1.37$ \\
Female & 1.00 & \\
Analgesic use & & $0.97-1.83$ \\
Yes & 1.33 & \\
No & 1.00 & \\
Underlying disease & & $0.68-1.34$ \\
Any & 1.00 & \\
None & & \\
Abdominal CT or sonography in 6 months & & $0.96-3.89$ \\
Yes & 1.00 & \\
No & & \\
Severity & 1.93 & \\
High triage acuity & & \\
Low triage acuity & 1.00 & \\
\hline
\end{tabular}

$\mathrm{CT}$, computed tomography; ED, emergency department.

$\mathrm{P}<0.001)$. In the abdominal pain group, the use of CT was less frequent in the pediatric $E D$, but this difference was not statistically significant ( $27.3 \%$ vs. $21.2 \%, P=0.091)$. In the headache group, visits to the general ED was the only statistically significant risk factor for undergoing a CT scan, with an OR of $4.97(95 \% \mathrm{Cl}$, 1.91 to 12.94). In the abdominal pain group, none of the measured factors were significantly related to $\mathrm{CT}$ scans.

\section{DISCUSSION}

We found that the use of CT was more frequent among the adolescent patients with headache or abdominal pain who attended the general ED than among those who attended the pediatric ED. Although several studies have demonstrated an increased frequency of CT use in non-pediatric facilities, ${ }^{9,10}$ this study is unique in that the rates of $\mathrm{CT}$ use in adolescent patients were different in two EDs even within the same tertiary hospital.

Thanks to several efforts, such as the Image Gently Campaign, that helped increase the awareness on the radiation risks associated with $\mathrm{CT}$ scans of pediatric patients, there has been a decline in the frequency of $\mathrm{CT}$ examinations in pediatric patients visiting 
the ED. ${ }^{7,8}$ However, the frequency of CT use in adolescents has been reported to be similar to that in adult patients and higher than that in younger age groups. ${ }^{2,8,11}$ Many EM physicians consider the risk of radiation exposure in adolescents comparable with that in adults or that adolescent patients require a diagnostic approach similar to that applied in adult patients. In the present study, the frequencies of CT use were different for adolescents with headache or abdominal pain between the general and pediatric EDs in the same hospital. This result seems to reflect the manner in which the adolescents who visited the general ED were considered as adult patients.

We compared the incidence of CT use in patients with headache or abdominal pain. Both symptoms are not only among the most common complaints that require CT examination for etiological evaluation in the pediatric ED, but they have also caused a recent increase in CT scans. ${ }^{2,11}$ Specifically, the guidelines for the selection of low-risk groups that did not require imaging in the past studies have been changed in the case of patients with headaches. $^{12,13}$

In the ED, other available image modalities without the radiation hazards of CT include magnetic resonance imaging and ultrasonography in patients with headache or abdominal pain. We also found that the use of magnetic resonance imaging and ultrasonography were less frequent in the general ED than in the pediatric ED (headache: 15 [9.5\%] vs. 33 [13.3\%], $\mathrm{P}<0.371$; abdominal pain: 6 [1.8\%] vs. 36 [12.8\%], P<0.001). In Seoul National University Hospital, the adolescent patients in both general and pediatric EDs were requested to undergo ultrasound in the department of radiology. Results showed that there is no difference in the accessibility of ultrasound enforcement between the two EDs. This suggests that the pediatric ED is trying to use diagnostic modalities with lower radiation hazards.

In the whole abdominal pain group, the rate of positive CT findings in the general ED was higher than in the pediatric ED. These differences may be the result of more use of ultrasonography in patients with abdominal pain in the pediatric ED and no CT scan if they were positive on ultrasonography. In fact, when we analyzed the data on 24 patients who had positive findings on ultrasonography performed in the pediatric ED, the rate of positive findings between the two EDs (17.7\% vs. $14.9 \%, P=0.245)$ had no significant difference.

This study had several limitations. First, the results reported in this study were taken from a single institution and may not reflect the patterns of use across the nation or other geographic regions. Second, in the event of ED crowding or lack of resources, the advice of a triage nurse or emergency physician may have influenced the selection of the ED. However, since the place where the patient or the caregiver chooses the ED was in the registration counter of each ED, the possibility of receiving intervention from the nurse or emergency physician would be very low and depended purely on the choice of the patient and the caregiver.

In both EDs, the primary decision to use $\mathrm{CT}$ is made by EM residents. Thus, we assume that there are little differences in the decision made by EM residents because they rotate in both EDs and have similar experiences. However, in addition to education about radiation hazards that are constantly communicated through ED rounds, journal reviews, or direct faculty observation, the environment in the pediatric ED, which influences the decision to perform CT examinations or not, may have had an impact on the practice pattern of the residents working there.

Our study is the first to report on the variation in CT use between general and pediatric EDs in the same tertiary hospital. We demonstrated that the decision to use CT on adolescent patients might be different even within the same hospital depending on the differences of awareness on the radiation risks from CT. We suggest that child-friendly environments and policies should be considered as essential for reducing radiation exposure in the ED.

The Image Gently Campaign and the ALARA (as low as reasonably achievable) concept in pediatric CT studies have provided the opportunity to elevate the attention and awareness of radiation exposure. $^{14,15}$ Even outside the US, where such campaigns have not been conducted, pediatric EDs are well aware of the radiation hazards that pediatric patients can be exposed to during CT scans. This awareness is also evident in the recent decline in the CT scan rate of pediatric emergency patients in Korea. ${ }^{8} \mathrm{~A}$ change in the awareness of the substantial problem of radiation exposure not only in younger children but also in adolescents would be the first step toward reducing the radiation exposure of adolescents.

\section{CONFLICT OF INTEREST}

No potential conflict of interest relevant to this article was reported.

\section{REFERENCES}

1. Brenner DJ, Hall EJ. Computed tomography: an increasing source of radiation exposure. N Engl J Med 2007;357:227784.

2. Broder J, Fordham LA, Warshauer DM. Increasing utilization of computed tomography in the pediatric emergency department, 2000-2006. Emerg Radiol 2007;14:227-32.

3. Brenner D, Elliston $C_{1}$ Hall $E_{1}$ Berdon W. Estimated risks of radiation-induced fatal cancer from pediatric CT. AJR Am J Roent- 
genol 2001;176:289-96.

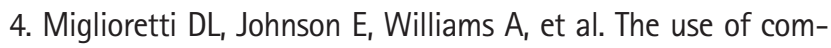
puted tomography in pediatrics and the associated radiation exposure and estimated cancer risk. JAMA Pediatr 2013;167: 700-7.

5. Chodick G, Ronckers CM, Shalev V, Ron E. Excess lifetime cancer mortality risk attributable to radiation exposure from computed tomography examinations in children. Isr Med Assoc J 2007:9:584-7.

6. Lodwick DL, Cooper JN, Kelleher KJ, Brilli R, Minneci PC, Deans KJ. Variation in utilization of computed tomography imaging at tertiary pediatric hospitals. Pediatrics 2015;136:e1212-9.

7. Menoch MJ, Hirsh DA, Khan NS, Simon HK, Sturm JJ. Trends in computed tomography utilization in the pediatric emergency department. Pediatrics 2012;129:e690-7.

8. Oh HY, Kim EY, Kim JE, et al. Trends of CT use in the pediatric emergency department in a tertiary academic hospital of Korea during 2001-2010. Korean J Radiol 2012;13:771-5.

9. Larson DB, Johnson LW, Schnell BM, Goske MJ, Salisbury SR, Forman HP. Rising use of CT in child visits to the emergency department in the United States, 1995-2008. Radiology 2011;
259:793-801.

10. Hryhorczuk AL, Mannix RC, Taylor GA. Pediatric abdominal pain: use of imaging in the emergency department in the United States from 1999 to 2007. Radiology 2012;263:778-85.

11. Fahimi J, Herring A, Harries A, Gonzales R, Alter H. Computed tomography use among children presenting to emergency departments with abdominal pain. Pediatrics 2012;130:e106975.

12. Pickering $A$, Harnan $S$, Fitzgerald $P$, Pandor $A$, Goodacre S. Clinical decision rules for children with minor head injury: a systematic review. Arch Dis Child 2011;96:414-21.

13. Stiell IG, Wells GA, Vandemheen $K$, et al. The Canadian CT Head Rule for patients with minor head injury. Lancet 2001;357: 1391-6.

14. Goske MJ, Applegate KE, Boylan J, et al. The Image Gently campaign: working together to change practice. AJR Am J Roentgenol 2008;190:273-4.

15. Don S, Macdougall $R$, Strauss $K$, et al. Image gently campaign back to basics initiative: ten steps to help manage radiation dose in pediatric digital radiography. AJR Am J Roentgenol 2013;200:W431-6. 